\title{
DEFUNTA MORTE: LUTO, SOBREVIDA, RESSURREIÇÃO
}

\author{
Deceased Death: Mourning, Survival, Resurrection
}

Jacob Rogozinski

Universidade de Strasbourg

Estrasburgo, França

\begin{abstract}
Resumo
Tendo como objetivo compreender o motivo derridiano da sobrevida, este artigo propóe a análise da concepção de morte que encontramos na obra de Jacques Derrida e do diálogo que ela estabelece com o pensamento ocidental, especificamente a respeito desse tema, em Hegel, Heidegger, Nietzsche etc. A discussão se concentra em duas aporias com as quais Derrida se confrontou: a aporia do relevamento [relève] e a aporia da finitude. Após examinar o lugar do pensamento derridiano da morte no âmbito da tradição filosófica, o trabalho procura mostrar que as relaçóes de Derrida com a literatura - representada aqui pelas obras de Maurice Blanchot e Antoine Artaud são capazes de oferecer uma espécie de resposta a essas aporias e de iluminar a visão da morte apresentada pelo filósofo francês.
\end{abstract}

Palavras-chave: Derrida; morte; sobrevida; luto; desconstrução.

\section{Résumé}

Dans le but de comprendre le motif derridien de la survie, cet article se consacre à l'analyse de la conception de la mort prévalant dans l'œuvre de Jacques Derrida et au dialogue que celle-ci établit avec la pensée occidentale sur ce thème (Hegel, Heidegger, Nietzsche etc.). La discussion se concentre sur deux apories auxquelles Derrida s'est confronté: l'aporie de la relève et l'aporie de la finitude. Après avoir examiné la place de la pensée derridienne sur la mort dans le cadre de la tradition philosophique, on cherche à montrer que les rapports de Derrida à la littérature - représentée ici par les œuvres de Maurice Blanchot et d'Antoine Artaud - sont capables d'offrir une sorte de réponse à ces apories et de jeter de la lumière sur la vision de la mort présentée par le philosophe français.

Mots-clés: Derrida; mort; survie; deuil; déconstruction.

\section{Abstract}

In order to understand the Derridean idea of survival, this paper analyses the concept of death developed by Jacques Derrida, as well as the dialogue that this concept establishes with western thought (Hegel, Heidegger, Nietzsche etc.). The discussion emphasizes two aporias focused by Derrida: the aporia of relève and the aporia of finitude. After examining the place of Derrida's concept of death in relation to philosophical tradition, the paper aims to show that the relations between Derrida and literaturerepresented here by the works of Maurice Blanchot and Antoine Artaud - are able to give a kind of reply to these aporias, as well as to clarify the idea of death presented by the French philosopher.

Keywords: Derrida; death; survival; mourning; deconstruction. 
Defunta morte (Feula mort): é, primeiramente, uma citação indireta, uma alusão ao título de um livro de Derrida, Defunta cinza (Feula cendre), admirável meditação sobre o resto, o luto, o sacrifício e o holocausto, a "dispersão sem retorno". Lá, a incineração é a marca daquilo que resiste ao trabalho do luto, de uma "afirmação de fogo sem lugar nem luto" (DERRIDA, 1987: 43). Mas a cinza não é a morte, e nem toda morte deixa forçosamente cinzas: há diversas maneiras de morrer, diversas maneiras de pensar a morte. Defunta cinza ou Defunta morte: os títulos jogam com a homonímia, com os dois sentidos da palavra francesa "fogo" [feu], cuja ambiguidade semântica recobre talvez duas relaçôes diferentes com a morte. "Fogo", em nossa língua, designa mais frequentemente $o$ fogo, a chama que aquece e destrói, e, por derivação, a ordem mortal de abrir fogo. Entendida dessa maneira, a expressão "fogo à morte" ressoaria como uma declaraçáo de guerra: "ao fogo, a morte!", "fogo à morte!". Nós sabemos que o termo "fogo" se emprega igualmente em francês em uma locução um pouco obsoleta para qualificar um defunto: "Finado fulano" [feu Untel]. Nesse caso, o título não se deixaria mais entender como uma palavra de ordem bélica, como este estranho e paradoxal enunciado: a morte está morta, a morte acabou. É que não se trata do mesmo fogo - o fogo enquanto chama derivado do latin focus, o foco, mas do "fogo" como designação de um defunto proveniente de fatum, o destino. Com efeito, "finado fulano" se diz daquele que realizou seu destino, o inexorável destino de todo homem, de todo ser vivo, que é de morrer. O que implica em uma certa concepção do destino humano, da existência como finitude, e assinala ao pensamento sua tarefa: de nos ensinar a morrer, de se exercitar ou de se antecipar a isso, conforme uma venerável tradição que iria de Platão e dos estoicos até Heidegger. Ela difere dessa outra concepção que se refere a uma vitória última sobre a morte, a ponto de anunciar a morte da morte. Visão ardente onde se trata de uma chama, de um "lago de fogo" no qual a morte seria atirada no fim dos tempos para ser consumida para sempre. Vocês reconheceram o kerygma final do Apocalipse de Joâo (20, 14-15), aquele anúncio escatológico que se opõe radicalmente ao outro pensamento sobre a morte, aquele que nos ensina a recebê-la bem, aceitando nossa finitude.

Onde Derrida se situaria nesse conflito, nesse desacordo entre dois pensamentos sobre a morte? Do lado da finitude, da aceitaçáo do destino e da antecipação do poder-morrer? Nada é menos certo. Ele já havia se oposto ${ }^{1}$ ao apocalipse, ao anúncio e ao tom apocalípticos. Tomando como ponto de partida um escrito no qual Kant denuncia o "tom senhorial" dos "mistago-

\footnotetext{
${ }^{1}$ Em uma conferência no colóquio de Cerisy (1980), "Do tom apocalíptico adotado antigamente em filosofia”. In: DERRIDA, Jacques. Les fins de l'homme. Paris: Galilée, 1981, reeditado separadamente pela editora Galilée em 1983.
} 
gos", ele acabava por se interrogar sobre o "poderoso programa" que, ao longo da história ocidental, não cessa de "anunciar o fim". Ele se perguntava se é o tom, a escatologia, ou a voz mesma"; se toda voz não é a do "último homem" (a literatura é, entáo, brevemente convocada, com o nome de Blanchot, que nós vamos reencontrar daqui a pouco). Ele se perguntava finalmente se o apocalíptico não seria "uma condiçâo transcendental de todo discurso, de toda experiência mesmo, de toda marca ou de todo traço (...), quer dizer, do envio [envoi] divisível para o qual não há autoapresentação nem destinação assegurada" (DERRIDA, 1981:77-78). Afirmação que articula seus trabalhos precedentes sobre o envio ou a "destinerrância" e certos motivos que ele ia desenvolver em seguida, como a promessa e o messianismo, a "messianicidade sem messias". Mas sem nunca abordar o que está, entretanto, no coração do anúncio messiânico e/ou apocalíptico (supondo-se que essas duas noções se recobrem, o que não é certo): aquela promessa que, "aos olhos do messias, os mortos ressuscitarão". Que relação há entre tal promessa e a "lógica do luto", que ele nunca deixou de trabalhar? Sem esquecer essa visada enigmática de um "luto do luto", aquela de um "para além do princípio do luto", que é, dizia ele, "a única coisa que finalmente me interessa, aquela mesma que "me faz escrever e falar", "me dá e me tira o idioma". ${ }^{2}$ Fazer a experiência do luto remonta sempre - segundo a expressão do psicanalista Daniel Lagache - a "matar a morte" em nós: a traçar um limite entre o eu vivo e o morto, a fim de conseguir se separar do objeto perdido, introjetando-o, digerindo-o para melhor expulsá-lo - processo de introjeção que é importante distinguir da incorporação "críptica" do objeto morto no eu pela qual Derrida se interessou bastante. Matar $o$ morto fazendo o seu luto, seria essa a matriz dessa promessa messiânica de matar $a$ morte? Fazer seu luto não é a cada vez fazer seu luto da própria morte, proclamar aqui e agora a morte da morte?

Se não é que, ao afirmar o luto do luto ou a morte da morte, mantemos paradoxalmente a instância que se esperava revogar, a reforçamos mesmo ao duplicá-la, pois se trata ainda e sempre de fazer seu luto e/ou de levar à morte... Defunta morte não faz mais que enunciar esse paradoxo no qual a morte ganha de qualquer maneira. Provavelmente seria necessário confrontar tais enunciados às diferentes ocorrências daquele gesto derridiano que consiste em duplicar um conceito - a "verdade da verdade", o "relevamento [relève] do relevamento [relève]", a "doação do dom" etc. - como se esta duplicação permitisse extrair seu quase-transcendental. Defunta cinza, Defunta morte: em que lugar atópico, em que tempo pré-originário ou pós-terminal se situou para poder proclamá-lo? Em um tempo sempre por vir, aquele da profecia,

\footnotetext{
${ }^{2}$ Sobre esse motivo do "luto do luto", cf. entre outros Points de suspensions. Paris: Galilée, 1992: 54.
} 
do anúncio messiânico e apocalíptico, ou em um tempo sempre já passado, pois, nele, a cinza e o luto são o traço de um acontecimento de outrora, de uma chama apagada? E, sobretudo, quem ousaria enunciá-lo? Quem pode estar suficientemente vivo ou suficientemente morto para proferir não que "eu estou morto", como Derrida não cessou de escrever durante toda a sua vida, mas que a morte ela própria está morta, que o luto acabou? Declaração ainda mais inaudita que o eu estou morto do Valdemar de Poe, pois ela supóe um passo para além da morte. Quer dizer, uma sobrevivência. Mas de qual sobrevida se trata aqui? Que relação há entre o motivo derridiano da sobrevivência e aquela velha palavra - que ele quase nunca emprega - ressureição? Impossível abordar essa questáo sem se confrontar com a ambiguidade da sobrevivência; pois sobreviver e seus derivados são, em francês, tão ambíguos quanto o verbo "reviver". ${ }^{3} \mathrm{Um}$ sobrevivente é aquele que atravessou uma provaçâa na qual ele arriscou a vida e que retornou dela vivo. Todo sobrevivente é, nesse sentido, um "retornante" [ "revenant'], ainda que seu retorno não seja forçosamente o de um fantasma: isso pode ser também a sobrevida de um vivo que afrontou vitoriosamente a morte. Eis porque um sentimento de triunfouma exaltação maníaca - caracteriza frequentemente a experiência do sobrevivente e pode torná-la temível para si mesmo e para os outros. Numerosos exemplos o atestam: sobreviver pode enlouquecer, sobreviver pode levar a se matar e a matar. Este seria o momento, se nós tivéssemos tempo, de examinar aquelas páginas surpreendentes de Massa e poder nas quais um judeu que sobreviveu ao nazismo, Elias Canetti, se interroga sobre a "paixão de sobreviver" e a inquietante alegria que ela proporciona: ele vê nisso um tipo de "maldição" e a matriz das tiranias... (CANETTI, 1966: 241-295). Não nos esqueçamos, aliás, de que o verbo sobreviver designa igualmente em nossa língua o fato de permanecer em vida após ter perdido o que dava sentido a sua vida, seus próximos, seus amores, sua honra, até mesmo suas faculdades vitais: assim se diz, às vezes, daquele que perdeu tudo, que "ele sobreviveu a si mesmo". Compreendida dessa maneira, a sobrevida seria mais uma subvida, a existência quase-espectral de um vivo já quase morto, de um mortovivo. Essa ambiguidade persiste quando se passa a uma outra língua? Ela se resolve, ao menos parcialmente, na dualidade das expressóes verbais que traduzem "sobrevida" em alemão (überleben / fortleben) ou em inglês (que apresenta três possibilidades: to survive / to live on / to outlive)? ${ }^{4}$

Retomando esse termo para fazer dele um motivo maior de seu pensamento, Derrida herda sua significação ambígua, que ele jamais questiona. Ele

\footnotetext{
${ }^{3}$ F. Worms explorou o jogo duplo dessa expressão em seu belo livro Revivre. Paris: Flammarion, 2012.

${ }^{4}$ Questão que não é somente uma "questão de tradução" e que eu devo a uma observação de Sam Weber.
} 
chega a apresentar a "sobrevida" como uma vida hiperbólica, um excedente de vida, e o prefixo sobre ressoa, entâo, com um acento quase nietzschiano. Notadamente, é o caso da entrevista na qual ele declara - algumas semanas antes de sua morte - que "a desconstrução está do lado do sim, da afirmação da vida", que "sobreviver à morte (...), é a vida mais intensa possível" (DERRIDA, 2005: 38.). Mas essa declaração, a despeito de seu caráter quase testamentário, não nos dá forçosamente sua última palavra, a verdade última ou o segredo enfim desvelado de sua obra (se pudesse haver um...). Nós que gostávamos tanto dele, nós teríamos gostado muito que seu sim, venha fosse um sim à vida, que seu pensamento fosse uma "atanatologia", uma meditação da vida e não da morte, a afirmação de uma "vida anterior à oposição da vida e da morte". ${ }^{5}$ E, contudo, nem sempre é o caso: em seus textos anteriores, a sobrevida quase nunca é determinada como sobre-vida, ressurgência da vida em sua mais extrema intensidade. Ao invés de aproximar um pouco artificialmente Derrida de Nietzsche, de Bergson, de Rosenzweig ou de Henry, convém constatar suas ambiguidades, suas hesitaçôes, e até suas contradiçôes, evitando passar em branco sobre essa melancolia da desconstrução, essa tentação tanatológica à qual seu pensamento sobre a sobrevivência se submete tão frequentemente à autoridade da morte. Talvez porque ele caracterizava - um pouco apressadamente - o logocentrismo como um zoologocentrismo, uma metafísica da Vida; e porque ele desconfiava de uma afirmação unívoca da vida, de uma vida que pretendesse se demarcar radicalmente da morte e acabar com ela, e não fosse finalmente mais que uma presença pura sem différance, quer dizer, um outro nome da morte. Pois a "vida pura", dizia, é sinônimo da "morte pura" - "e tudo o que eu digo vai tanto contra uma filosofia da vida quanto contra seu simples contrário" (DERRIDA, 1996a: 50.). O que explica que, mais frequentemente, ele identifique o sobrevivente, o retornante e o espectro; que ele entenda a sobrevida como a existência espectral de um nem-vivo-nem-morto que sobrevive a si mesmo sem jamais ter sido si-mesmo. Pois “o sobrevivente é sempre um fantasma” (DERRIDA, 1986a: 161.), sempre em luto de si mesmo, em luto dessa singularidade única, insubstituível, que ele nunca foi, pois ele carrega o luto "desde a morte de quem nunca foi vivo" (DERRIDA, 1974: 26).

Impossível compreender alguma coisa sobre o motivo derridiano da sobrevida sem levar em conta esse combate, que ele nunca deixou de realizar em duas frentes, para diminuir a pressão de um double-bind onde, até o

\footnotetext{
${ }^{5}$ É a orientação que defendem generosamente, mas muito apressadamente a meu ver, muitos leitores de Derrida: penso notadamente em meus amigos A. David (cf. Rue Descartes, n. 48, 2005 : 111-115), G. Bensussan (cf. "Oui, la survie", Rue Descartes, n. 52: 53-62) e F. Worms (em uma conferência ainda inédita intitulada "La Simplicité de Derrida").
} 
presente, se encontrava aprisionado todo pensamento sobre a morte. Duplo impedimento que toma a forma de uma aporia duplicada: rapidamente, chamemos esses dois polos de a aporia do relevamento [relève] e a aporia da finitude. Ele se explicou a respeito da primeira aporia em A escritura e a diferença, e depois em Glas, mas é impossível para mim, nos limites deste texto, seguir o fio dessa longa e paciente explicação. Ele confrontou a segunda aporia no livro que carrega precisamente esse título, Aporias. Nele, ele questiona a concepção heideggeriana de uma apreensão antecipada de sua morte pelo Dasein, que o faria acessar sua "possibilidade mais própria", assegurando assim sua individuação mais radical. O que pressupóe que o Dasein possa atestar sua morte "como tal", se fazer testemunha de sua "própria morte", enquanto é necessário permanecer em vida para poder testemunhá-lo: pois é "como vivente ou morrente - morrente que permanece [demeurant] na vida - que ele atesta o ser-para-a-morte" (DERRIDA, 1996b: 96). A analítica existencial do Dasein tropeça assim no enigma de um nem-vivo-nem-morto, ainda em vida, no já aí de sua morte, que é precisamente a sobrevivência como luto de si. Ora, Heidegger "não quer saber do retornante e do luto". Ao querer fundamentar a ipseidade do Dasein na antecipação de sua morte por vir, o autor de Ser e tempo náo reconheceu uma outra possibilidade: que essa ipseidade fosse constituída a partir de um luto originário", que seria ao mesmo tempo um luto de si e um luto do outro; de tal forma que "sua relação consigo mesmo acolhesse ou supusesse o outro dentro de seu ser-si-mesmo" (DERRIDA, 1996b: 111). Sua ipseidade se descobre então irremediavelmente fendida, fraturada por essa relação pré-originária com o outro, pela estrutura de uma auto-hétero-afeição irredutível. É essa alteração pré-originária do si-mesmo que Heidegger - diferentemente de Levinas, talvez já de Hegel - não chega a pensar. Tampouco chega a apreender a torção temporal implicada no luto de si originário, esse morrer que Blanchot designa por vezes como "a iminência incessante (...) do que sempre já passou”.

Nem Hegel, nem Heidegger: como escapar da dupla aporia da qual esses dois nomes são índices? Como desfazer a aporia da finitude sem desaguar na aporia do relevamento? Evitando o gesto inverso, pelo qual o pensamento seguramente cairia também na armadilha; pois trata-se de superar essas duas aporias: mesmo que ele a tenha apresentado por vezes como uma "provação aporética”, faríamos um desserviço à desconstrução pretendendo que ela deva simplesmente se instalar na aporia ao invés de buscar atravessá-la. Quando ele tenta se subtrair às aporias da filosofia, recorre frequentemente à literatura; por exemplo, jogando Mallarmé "contra" Platão, ou melhor, no lugar de Platão, Bataille e Genet no lugar de Hegel ("no lugar de": o que não quer dizer que a literatura assumiria o lugar reservado à filosofia, mas, sobretudo, 
que ela a desestabiliza sem substituí-la). Para afrouxar o double-bind do finito e do infinito, do ser-para-a-morte e da vida absoluta, é a Blanchot que ele se refere, à sua afirmação de um "sobreviver sem sobreviver" - entendam: sem excedente de vida - na qual se revela a contaminação indecidível da vida e da morte. Lendo Blanchot, ele sublinha que "se quiséssemos a todo custo falar aqui de ressurreição (...), não haveria nem cristologia nem Sexta-feira Santa especulativas, nem verdade da religiáo no saber absoluto (...). Mas tudo isso, a Paixão, a Ressurreição, o Saber absoluto são imitados, repetidos e deslocados (...) na vida sem vida dessa sobrevivência” (DERRIDA, 1996c: 45-46). Blanchot no lugar de Hegel: o morrer sem morte de uma sobrevida sem vida mais que o relevamento [relève] da morte na autoafirmação da Vida absoluta. Mas também Blanchot no lugar de Heidegger, pois a provação da morte da qual ele se faz a testemunha dissolve a singularidade e a identidade do em Si na experiência de uma morte anônima onde eu "não morro, eu sou destituído do poder de morrer, (onde) se morre, não se cessa e náo se termina de morrer" (BLANCHOT, 1955: 160). Lidamos, precisa Derrida, com "uma morte que, por ser insubstituível, e porque ela é única, nem mesmo é individual, (...) proposição que inquietaria até esta Jemeinigkeit, esse 'cada vez meu'” do Dasein heideggeriano (DERRIDA, 1996c: 38). É esta neutralização da vida/ morte que ele observa em uma narrativa de Blanchot, $O$ instante da minha morte, que coloca em cena o que se poderia chamar uma morte sem morte $d a$ morte. Narrativa de estilo autobiográfico - ou sobretudo "autotanatográfica" - que conta um episódio ocorrido pouco antes da Liberação. Pouca importância tem aqui se se trata de um testemunho autêntico ou fictício. "Eu me lembro de um jovem (...) impedido de morrer pela morte mesma”. Suspeito de participar da Resistência, o narrador anônimo havia sido preso pelos alemães e levado a um pelotão de execuçáo. No momento em que o "tenente nazista" ia gritar "fogo!", ocorre "um outro 'fogo', um contrafogo", um fuzilamento desencadeado pelos Resistentes. É então que os soldados deixam partir o narrador, que se vê assim vivo para além de sua morte, assombrado para sempre pela experiência impossível dessa morte que não ocorreu, que ocorreu sem ter ocorrido, que só aconteceu por não acontecer. Longe de libertá-lo ou devolvê-lo à vida, essa "interrupção do morrer" o deixará para sempre em instância de morte, de uma morte que não é sua própria morte, que o priva de toda identidade própria consagrando-o à sobrevivência de um viver sem vida. Ao que Derrida propóe nomear a permanência [demeurance], onde convém entender não somente "o que se hospeda e se mantém através do tempo em uma morada [demeure]", mas também "a experiência não experimentada de quem morre, lá onde dois permanecem [demeurent], não morrem [ne meurent pas $]$ (...) ou des-morrem [dé-meurent $]$ no momento em que eles 
morrem" (DERRIDA, 1996c: 55). Morrer sem morrer - e portanto sobreviver - no instante mesmo em que se morre, nesse instante que não terminará mais de terminar, se estende monstruosamente até durar todo o tempo de uma vida. Tal é a provação de uma permanência, do des-morrer sobre o qual Blanchot nos fala.

A esta altura, duas séries de questóes se impóem:

- (1) Nós reencontramos aqui o que Derrida já havia observado anteriormente em Blanchot, a insistência de um $X$ sem $X$ ("nome sem nome", "infelicidade sem infelicidade", "ser sem ser"...) que culmina em uma série de enunciados sobre a vida/a morte: "morte sem morte", "sobreviver sem sobreviver", "viver sem o vivo como morrer sem a morte" etc. (DERRIDA, 1986a: 91). Provavelmente seria necessário confrontar essa lógica do X sem $\mathrm{X}$ com o gesto derridiano da duplicação quase transcendental (ao modo $X$ de $X)$. Ocorre com ele, aliás, de ele mesmo conjugar os dois gestos, por exemplo, quando fala da "verdade sem verdade da verdade". O que ocorre, portanto, quando o X de X se entrelaça com o X sem X e se deixa contaminar por ele? O motivo blanchotiano do Neutro, é certo, em nenhum caso pode se reduzir a uma simples anulação das oposiçóes. Ele implica, apesar de toda sua neutralização, no modo de um nem/nem, e Derrida valida esse gesto em diversas passagens decisivas de sua obra. Sobreviver, nesse sentido, não é nem viver nem morrer, assim como o pharmakon não é nem simplesmente remédio, nem unicamente veneno. O que essa neutralização dos opostos impede de vislumbrar é a sua posição dissimétrica no seio de sua oposição, o primado de um termo sobre um outro, a preferência que se poderia decidir dar à vida sobre a morte (ou à morte sobre a vida). Quando ele se esforçava para descrever a "estratégia geral da desconstrução", seu gesto-duplo ou sua cena dupla, Derrida sublinhava entretanto que ela deve evitar se limitar à "simples forma do nem/nem", de "neutralizar simplesmente as oposiçóes binárias da metafísica", desconsiderando assim sua dissimetria e a inversão necessária de sua hierarquia (Cf. DERRIDA, 1972: 56-57). Teria ele se dado conta suficientemente dessa exigência? Deixando-se cativar pelo X sem X de Blanchot, não teria ele cedido com muita frequência a isso que eu chamarei de bom grado (que me perdoem este mal Witz!) um ni-niilismo do indecidível? E quais seriam as consequências disso para a questão da qual nos ocupamos aqui? Se recusar, no entrelaçamento de a vida/a morte, a afirmar o primado da vida sobre a morte não equivale necessariamente a sustentar o primado inverso, a preferir a morte e a pensar a sobrevida - e até mesmo a própria vida - como um modo da morte?

- (2) $\mathrm{Na}$ experiência singular da permanência, que a narrativa de Blanchot coloca em cena, está em jogo uma certa relação com o nazismo, com 
tudo o que isso implica: o desastre absoluto, a "morte sem nome", aquilo que Derrida designa, lendo Celan, como a "ameaça de uma cripta absoluta" (Cf. DERRIDA, 1986b: 83; 94-96); mas sua leitura paciente e rigorosa da narrativa de Blanchot nunca o evoca. E contudo, essa sobrevivência espectral que se inscreve em filigranas em todos os escritos de Blanchot é mesmo tão diferente da insustentável provação da qual falava Adorno, essa "morte pior que a morte" cuja possibilidade o século XX nos mostrou? ${ }^{36}$ Ainda que Blanchot tenha abordado isso repetidas vezes, notadamente em $A$ escritura do desastre, trata-se de uma pista que Derrida não seguirá. Sabemos que, contrariamente a Lyotard, a Lacoue-Labarthe (para falar apenas de próximos), ele deixou essa cripta selada. Se pudéssemos ter a medida disso pelo pensamento e pela escrita - mas somente isso é possível? -, todas as questóes colocadas aqui, essas aporias de a vida/a morte, do luto, do espectro, da sobrevivência, não deveriam ser profundamente reelaboradas? Como sobreviver à provação de uma morte pior que a morte? Como sobreviver para testemunhá-lo? Esse testemunho não seria ainda e sempre obra de um "sujeito", daquilo que Artaud chama um en sobrevivente? Enfatizando, na esteira de Blanchot, o anonimato do morrer e a espectralidade do sobreviver, a concepçáo derridiana da sobrevivência não corre o risco de desconsiderá-lo, de desviar-se dele?

Quem é o sobrevivente? Se alguém pudesse sobreviver ao instante de sua morte, ele ainda poderia dar testemunho disso em primeira pessoa? Blanchot optou por manter anônimo o narrador de sua narrativa, provavelmente porque ele havia constatado há muito tempo esse luto de si, essa neutralização do Eu na instância anônima do Morre-se. Em O instante da minha morte, essa destituição do Eu assume a forma de um diálogo, ou, mais ainda, de uma interpelação do Eu por um outro "sujeito", uma outra voz, tão anônima quanto: "Eu estou vivo. Não, você está morto". Basta dizer, observa Derrida, que "o que foi eu não é mais eu, o ego cogito" e "o que separa as duas identidades egológicas não é nada menos que a morte ela mesma”" (DERRIDA, 1996c: 48.Cf. também: 68-69). A insustentável provaçáo de uma morte sem morte divide irrevogavelmente o "eu" de si mesmo, o desdobra em um eu afirmando que é vivo e um tu que o interpela como já morto; o que o impede de se reunir na consciência-de-si do sujeito hegeliano ou na ipseidade finita do Dasein heideggeriano. Lição bastante vizinha daquela que Derrida havia tirado do Valdemar de Poe: o enunciado impossível eu estou morto significa ao mesmo tempo a morte do Eu, seu retorno enlutado e espectral. Segundo um gesto de destituição do ego que ele compartilha com outros contemporâneos - Sartre, Bataille, Lacan, Deleuze... - e que propus chamar de egocídio. Gesto que se

6"Dizer que a morte é sempre a mesma é tão abstrato quando não-verdadeiro (...). A morte nos campos de concentração é um horror novo: a partir de Auschwitz, a morte significa ter medo de alguma coisa pior do que a morte" (ADORNO, 1978: 290). 
liga sempre, de uma maneira ou de outra, a uma tanatologia, quer dizer, à preferência dada à morte sobre a vida. Não seria o caso aqui de desenvolver todas as implicaçóes de um tal gesto, de expor seus pressupostos e limites. ${ }^{7}$ Mas simplesmente de lembrar que essa (não) experiência da morte que foi aquela de Blanchot não é a única que a literatura e as artes de nosso tempo atestam; que uma outra relação com a vida/a morte, uma outra sobrevivência são possíveis. É impossível para mim analisar aqui, dentre tantos outros exemplos significativos, o papel que essa travessia da morte pode desempenhar no percurso de dois artistas plásticos contemporâneos, dois pilotos de guerra, um americano e o outro alemão - Sam Francis e Joseph Beuys -, ambos vítimas de um acidente de aviáo e que tiraram do morrer-sem-morte de um coma traumático a matéria de toda sua obra. Eu me contentarei em evocar, muito brevemente, a atestação que um poeta nos dá disso: "Eu estou morto há muito tempo", escreve, nos anos vinte, Antoine Artaud, "eu estou suicidado, me SUICIDARAM" - e, alguns anos mais tarde, "eu sempre soube que eu era Artaud, o morto" (ARTAUD, 1925: 20; 1980: 202). Com efeito, ele se considera como uma "múmia de carne fresca", um "natimorto", consagrado à sobrevivência espectral de quem "não é nem morto nem vivo". Tantos enunciados autotanatográficos onde se afirma o estranho conhecimento de um luto anterior de si mesmo, de um devir-neutro de "sua" morte, que o situariam perto do "morre-se" de Blanchot. Não fosse o fato de que, a partir de um certo momento - que coincide com sua travessia da loucura, sua "cura" (se este termo convém aqui), seu retorno do hospício de Rodez - tais enunciados vão dar lugar à afirmação de uma vida mais potente que a morte: "eu atravessei a morte, a escura morte pela vida, e continuar morto é trair a vida" (ARTAUD, 1945: 265). Como Blanchot e tantos outros, Artaud se vê, com efeito, como um sobrevivente, em meio a uma "nuvem de eu sobreviventes"; mas ele identifica desde entáo sua sobrevida a uma ressurgência de vida: o cruzamento de um limite, desse ponto que ele nomeia o "ponto de morte" ["point de mort"] e que designa também a "não-morte" [ "pas-de-mort"], a inanidade ou a impostura da morte. Se ele continua a afirmar uma preferência, ou, mais ainda, uma precedência, não é mais aquela da morte na torção temporal de um luto anterior, vista como uma re-criação contínua, re-nascimento perpétuo: trata-se de "nascer para a vida na vida. Pois a cada instante vivido nós precedemos nosso próprio nascimento" (ARTAUD, 1945: 265). Como compreender esses enunciados inauditos? Como os de Blanchot, eles se enraízam em uma experiência pessoal: aquela de sua ruína na Irlanda, de

\footnotetext{
${ }^{7}$ Sobre essa questão, permito-me remeter à primeira parte de Le moi et la chair. Paris: Cerf, 2006; bem como a Cryptes de Derrida. Fécamp: Lignes, 2014.

${ }^{8}$ Tentei descrever a lógica paradoxal da relação de Artaud com a morte em Guérir la vie. Paris: Cerf, 2011.
} 
sua internação em diversos hospícios, da provação dos eletrochoques no hospício de Rodez, de seu retorno à escrita, essa "cura" que ele vive como ressurreição. E contudo, tanto quanto as de Blanchot, sua escrita e seu pensamento não se deixam "explicar" por circunstâncias auto-bio-tanatográficas. É necessário observar em Artaud, como Derrida algumas vezes sugeriu, o fantasma de uma parúsia absoluta, a marca de uma metafísica da vida, de uma vida sem morte; quem imaginaria que ela acabou com os espectros e com o luto e que restaria assim cativa da concepção cristã da ressurreição e da salvação?? Nada impede de crê-lo. Senáo, talvez, alguns enunciados do próprio Artaud, onde ele afirma a irredutível ligação de a vida/a morte na existência e no poema, seu entrelaçamento ou seu quiasmo, mas sob o primado da vida: pois "o segredo de minha existência é que eu sou um pedaço morto de madeira sempre vivo", "tão mais vivo quanto ele está morto" (ARTAUD, 1947: 84; 245). Não era essa sua maneira singular de afirmar a sobrevida, de preferir sempre a vida?

Tradução de Eduardo Veras

Referências bibliográficas

ARTAUD, Antonin. Euvres complètes, t. II. Paris: Gallimard, 1980.

. Euvres complètes, t. XIV, v. 2. Paris: Gallimard, 1947.

. Euvres complètes, t. XVII. Paris: Gallimard, 1945.

. Euvres complètes, t. I, v. 2. Paris: Gallimard, 1925.

BLANCHOT, Maurice. L'Espace littéraire. Paris: Gallimard, 1955.

CANETTI, Elias. Masse et puissance. Paris: Gallimard, 1966.

DERRIDA, Jacques. Apprendre à vivre enfin. Paris: Galilée, 2005.

. Résistances - de la psychanalyse. Paris: Galilée, 1996a. . Apories. Paris: Galilée, $1996 \mathrm{~b}$.

"Demeure". In: - Passions de la littérature. Paris: Galilée, 1996c.

. Feu la cendre. Paris: Ed. des Femmes, 1987.

. Parages. Paris: Galilée, 1986a.

. Schibboleth - pour Paul Celan. Paris: Galilée, 1986b.

. "Du ton apocalyptique adopté naguère en philosophie". In: NANCY, Jean-

Luc (Dir.). Les fins de l’homme. Paris: Galilée, 1981.

. Glas. Paris: Galilée, 1974.

. Positions. Paris: Minuit, 1972.

\footnotetext{
${ }^{9} \mathrm{Na}$ falta de um texto, refiro-me a uma intervençáo oral, feita no dia 14 de março de 1999, na ocasiāo de um colóquio sobre L'écriture et la mort organizado pelo Colégio Internacional de Filosofia.
} 
Jacob Rogozinski nasceu em Roubaix, França, em 1953. Foi professor no Colégio Internacional de Filosofia (Paris) e no Departamento de Filosofia da Universidade de Paris 8 (Vincennes, em Saint-Denis). Atualmente, é professor da Faculdade de Filosofia da Universidade de Strasbourg. Publicou, entre outras obras, Le don de la Loi: Kant et l'énigme de l'éthique (PUF, 1999), Le moi et la chair: introduction à l'ego-analyse (Cerf, 2006), Guérir la vie. La passion d'Antonin Artaud (Cerf, 2011) e Cryptes de Derrida (Éditions Lignes, 2014).

Recebido em: 15/09/2014. Aprovado em: 05/10/2014. 